$224|\operatorname{arq} \cdot \operatorname{vol} 19 \cdot \operatorname{no} 3 \cdot 2015|$ design

Now $(36$,

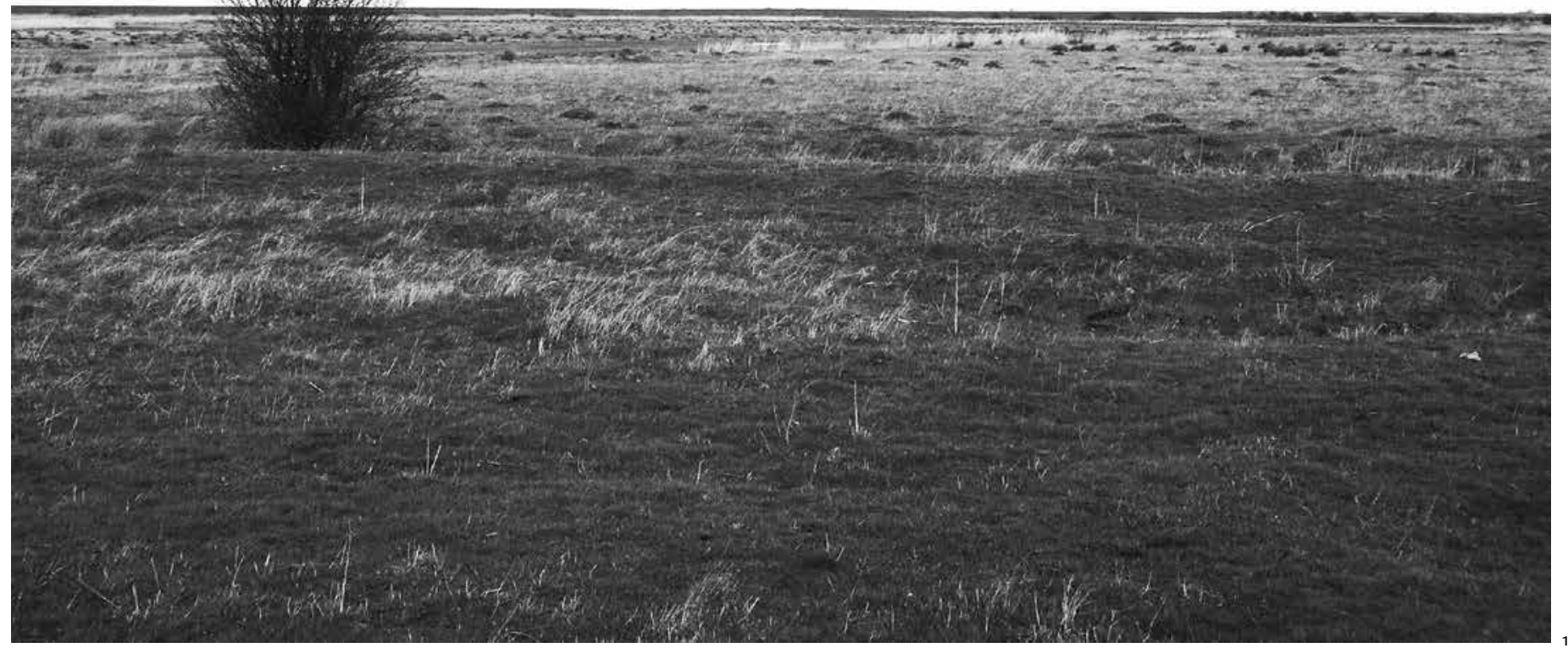

1 Photo of Landscape at Cliffe, Kent before reflooding process begins. 


\title{
A lyrical architecture of the flood: Landscape, infrastructure, and symbiosis
}

\author{
Matthew Butcher
}

Last October, the US-based Proceedings of the National Academy of Sciences (PNAS) published research led by the Australian National University, which revealed an unprecedented rise in sea levels over the past century - one that had not been surpassed in 6,000 years. ${ }^{1}$ This news came just months after the release of the Fifth Assessment Report of the

Intergovernmental Panel on Climate Change (IPCC), which stated with 'high confidence' that climate change will cause a worldwide spike in both coastal flooding and extreme precipitation. ' 'Increased economic losses', 'increasing sea levels', and 'coastal erosion' were highlighted as areas of key risk. The predictions put forward in these reports, in conjunction with extreme weather - as experienced in the east of England during the winter of 2013-14 for example, which saw some of the worst coastal flooding for 50 years - illustrate the need to investigate the form and applicability of our current flood defence.

In August 2011, the UK government's Environment Agency published TE2100, a report exploring and outlining the agency's response to the threat of coastal flooding in the UK due to global warming and its potential impact on the Thames Estuary east of London. ${ }^{3}$ The document contains a number of possible scenarios and solutions that could be fostered, including though not explicitly outlined as a complete and viable solution - examining the idea of giving landscapes over to flooding, such as historical coastal marshland, which could be used to absorb the threat of unexpected high tides and act as areas for flood water storage. Described as coastal realignment, the system works, in principle, when a sea wall is punctured in one or two places, allowing excess water caused by the swell in the tide to expand straight into the salt marsh. Ideally, the landscape of this new zone - a tidal marsh - should be populated with reed beds and other flora to help absorb the impact of the waves, thereby protecting land and sea defence from further flooding upstream. UK Projects have been set up to explore this particular solution including the Steart Peninsula in Somerset; Medmerry in West Sussex; and Abbotts Hall Farm in Essex. ${ }^{4}$ As the Environment Agency's flood and coastal risk manger Andrew Gilham stated in an interview with the BBC, 'Rather than fighting it [the flood waters], we are working with nature. ${ }^{5}$

While such methods of defence from the sea can be used as part of an overall strategy, the authors of the report state that it would not be sufficient on its own. ${ }^{6}$ It could be seen as part of a strategy to meet EU regulations concerning the reintroduction of tidal wetlands for the protection of plant and animal species (endangered by existing flood defences) rather than flood defence itself. Instead, the report suggests that the preferred option involves continuing improvements to existing defences and, following a review in 2050, a move towards larger mechanical flood defence barriers is possible. ${ }^{7}$ With the UK government's commitment of $£ 9$ billion to help regenerate the Thames Gateway - a scheme that includes the construction of hundreds of thousands of new homes, with many proposed in low-lying land - it is not difficult to imagine why an option that sets out to synthesise landscape and infrastructure, and lets the flood penetrate defence walls, may seem unattractive, particularly given that insurance companies are already rumoured to be nervous about insuring homes along the Thames Gateway ${ }^{8}$ but as Gilham has said, 'you can only keep building bigger and bigger defences for so long'. ${ }^{9}$

It could be said, then, that we have reached an impasse where, according to the plans laid out by TE2100, we are moving towards a scenario of reinforcing existing sea defences while also examining possibilities for larger and more efficient ones - the purpose of which is to ensure that land can be occupied for further urbanisation of the estuary. ${ }^{10}$ But, as more natural resources are expended to build both the proposed projects along the Thames Gateway and the defences that shield the consequences of global warming, the environmental footprint left behind remains. Sea levels will continue to rise - according to TE2100, anywhere from 20 to $90 \mathrm{~cm}$ in the next century. ${ }^{11}$

Perhaps there is another option. Perhaps by looking more closely at coastal realignment 


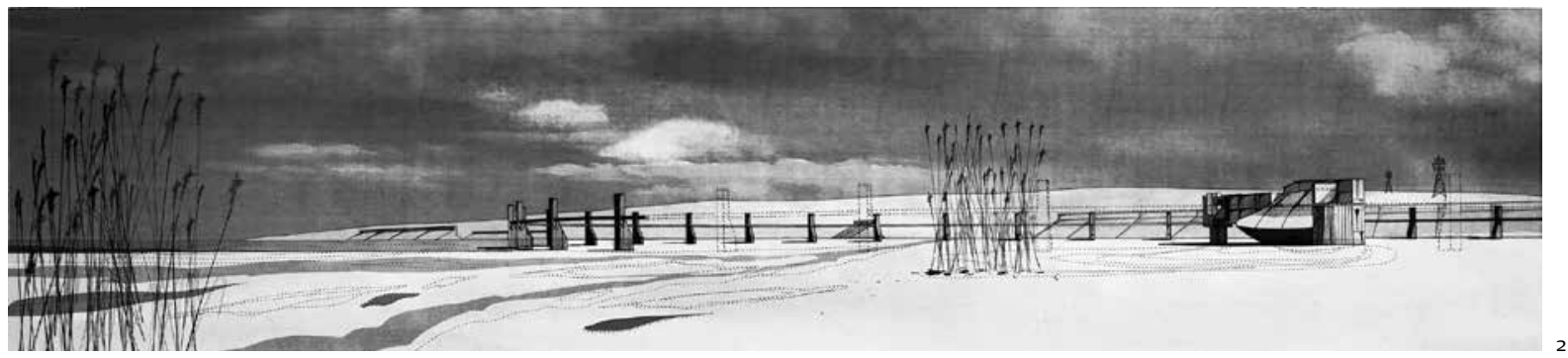

strategies we could begin to ask what formal and spatial logics might be appropriate for architecture if sited in a hybridised landscape like the tidal marsh? How might these logics mirror the particular conditions of this new model of infrastructure? And how might they contradict existing models of 'flood architectures' that are currently being built and developed?

There are, of course, numerous types of housing currently under discussion and under construction, which aim to provide architectures capable of responding to flood-prone environments. Among these are floating houses, such as those explored and built by Waterstudio in Holland, ${ }^{12}$ houseboats and even amphibious residences, including the UK's first Amphibious House, designed by $\mathrm{Baca}^{13}{ }^{13}$ which rises from its foundations during flooding and stays grounded when the landscape is dry.

These architectures tend to reinforce existing models of sea defence, however, and with it our current attitude to flooding. Existing as facsimiles of more conventional land-based dwellings, their form seems to be a manifestation of the denial of the threat from flooding. Water goes under or around these structures - inside remains inside, and the flood remains the flood. They provide engineered solutions to exist outside of, or on, the environment, not within it. On the other hand, water's role in coastal realignment forms a more complex system of relationships to the landscape: going 'through' the sea wall, and not stopping at the landscape threshold, but going 'into', and, again, 'through' it. This type of flood defence - where nature acts in conjunction with manmade strategies - creates a hybridised infrastructure. Developing these existing models, I would like to propose in this artile a move towards an architecture, which, much like the intertidal zone, exists in a symbiotic relationship with the ecosystems of the Thames.

\section{Threats from the sea}

This discussion is not new and it comes with its own specific historical precedents. These have been examined by Jonathan Hill in Immaterial Architecture. Hill states that 'Architecture is expected to be solid, stable and reassuring - physically, socially and psychologically. ${ }^{, 14} \mathrm{He}$ extends the argument that this condition developed with notions of house and home, as we now understand them, in seventeenthcentury Holland. He suggests that this development was a product of the Dutch fear of the unknown, whether the result of natural elements such as the flood, or a social consequence of the environment, such as crime. ${ }^{15}$ This is a condition that continues today, and it is a condition that, Hill argues, has resulted in the over-regulation of the practice and profession of architecture, therefore undermining creative approaches and innovation in design. 'As threats escalate and boundaries weaken, the desire for greater stability is evident [...] Rather than a creative engagement with new conditions, the realisation that a home is weak and becoming weaker often results in increasing desire for one that is strong. ${ }^{, 16}$ Today, however, it seems that fear is no longer tied as much to the unknown as it is to what is at risk. In the case of low-lying land, the outcome of a wet winter, and of rising sea levels, is apparent, both financially and to life. But, if we know that the flood can wash away the landscape, and the houses on it, and will continue to do so, why do we continue to reinforce the very defences that fail us?

\section{A space between}

As a means to explore the form of a more creative and symbiotic architecture of the flood, I would now like to turn to the work of Raimund Abraham (19332010) for three reasons. First, because midway through his career, he began separating himself from the propositions and provocations of the technologically sophisticated megastructures being explored by groups like Archigram to look more closely at an architecture investigating the origins of dwelling. Norbert Miller, writing in the monograph Raimund Abraham [Un]built, states 'In a significant departure from his visions of the city, Abraham returns in the early seventies to the primal vision of the House. ${ }^{, 17}$ These investigations were articulated as designs that expressed a co-dependent relationship between building, site, and landscape. Second, more critically, Abraham's primary interest could be said to have been the relationship of the poetic, or the lyrical and philosophical, to architecture. Third, Abraham expressed concern regarding the treatment and future state of the environment: 'we live in a time, when the air we breathe is so poisonous that we destroy the sculptures of our ancestors', he stated in a lecture given in $1991 .^{18}$ Each of these elements Abraham's conscious and contradictory shift to look at the origin of the dwelling, his interest in not only the physical but philosophical and lyrical aims of architecture, and his environmentalist approach allows for a deeper analysis of the more ephemeral and theoretical aspects of an architecture that can work symbiotically with the flood.

Abraham began an ontological investigation into the connection between landscape, architecture 
2 Perspective showing Silt House and Sediment Net Structure on Mud

Flats at Cliffe, Digital Collage, 2014

3 Exploded isometric of Silt House, Digital Collage, 2015.

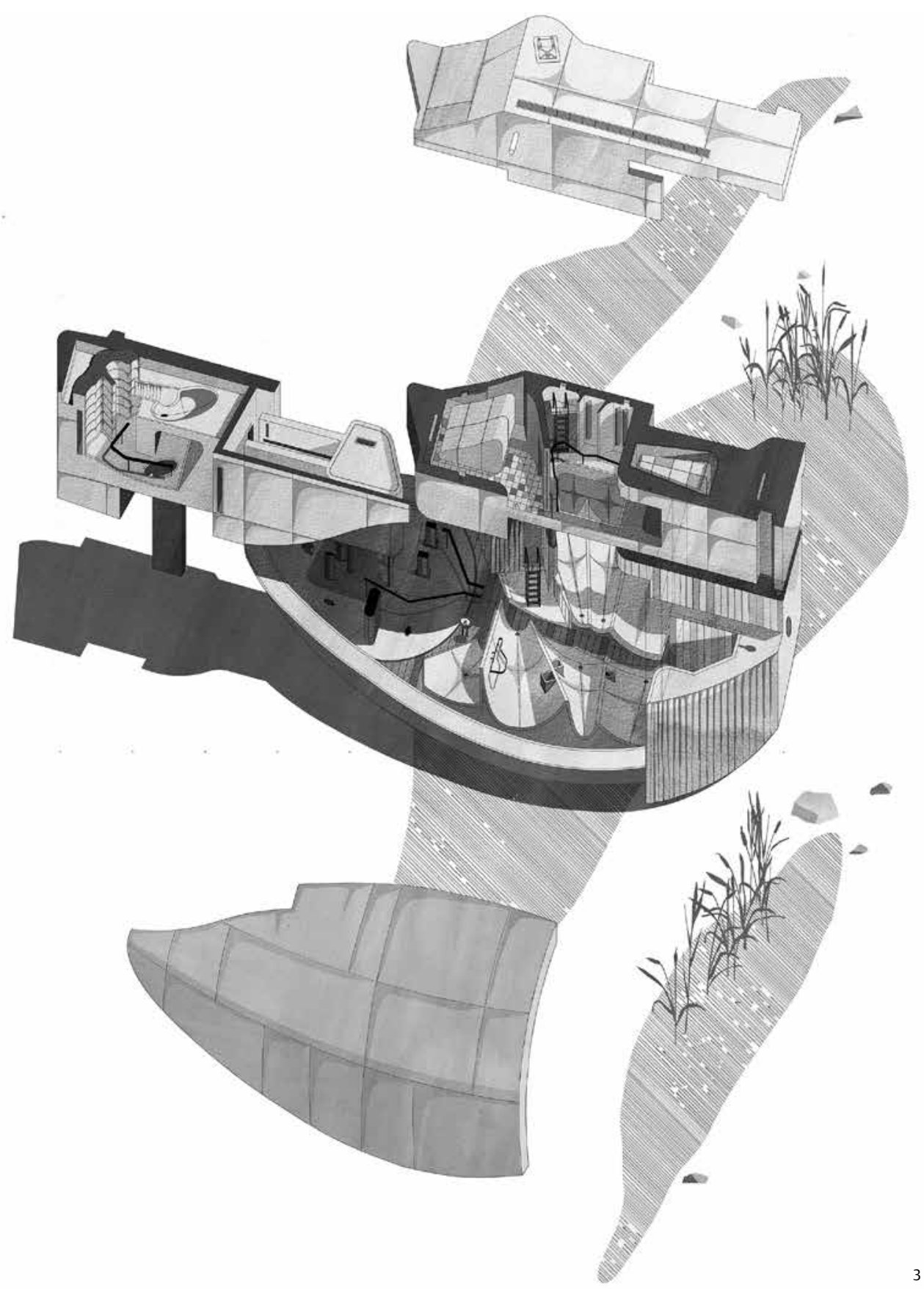

home and body in the late 1960 and early 1970 , focused on a series of drawn architectural proposals known as '10 Houses' - haunting propositions that partially bury architecture into a barren and unspecified desert landscape, making it part of the surrounding natural and environmental phenomena. Writing twenty years later, in 1992, he addressed the tension that comes with inserting built forms into the environment: 'Any architectural endeavour is an interference with this site. One either builds up into the sky or down into the earth. ${ }^{19}$ The idea comes across most explicitly in both The House with Curtains project (1972), in which walls are constructed from elements blown by the wind, and House with Flower Walls (1973), in which the physical enclosure is formed by the growth, and the process of decay, of flowers. Here the elements of the architecture are defined as much by traditional building materials as the elements of the wind and earth and the earth and mud of the ground.

Abraham's interest in this symbiosis could be seen as a means for investigating the origins of architecture and the origins of our dwelling within it. This was informed, in part, by a desire to explore the limits of architecture by returning to a history before it and to a space defined primarily by the body's interaction with landscape. Abraham was specifically influenced by the work of philosopher Martin Heidegger and, in a 1986 lecture, recounted that:

According to Heidegger the word design has two roots. The first one is signum, to signify, to set a signal. The second one is seccare, or cutting, plowing, scratching. I have always been more interested in the second definition because it logicallyleads to the place of interference, to the place where the earth is touched and the scratch eventually becomes the actual drawing. This is how physiological 
language turns into geometrical language. ${ }^{20}$ Four years later, in 1990, Abraham returned to this theme in an essay titled 'In Anticipation of Architecture', writing that 'intervention' is:

Born into the landscape [...] To touch it, to smell it, to let the eyes graze over it, to let the eyes dig into it, to scratch signs into the earth, to excavate cavities, to pile up mounds, to bury the entire body in the earth, to measure with groping steps, to feel space, to draw scales and to engrave them eternally into stone. ${ }^{21}$

In the same text he also states, 'The primal necessity to dwell becomes the necessity to transcend the notion of dwelling with the poetic desire to conquer and inhabit unknown abodes. ${ }^{22}$ Architecture, he believes, came out of the primal necessity to survive in unknown landscapes, to feel cold and to then find shelter. Taken in conjunction with Abraham's reference to Heidegger, another model of architecture begins to appear: one that not only negotiates the conditions of landscape symbiotically but which also expresses the idea that this particular form - the intervention which is woven into the environment - is analogous with what Abraham imagined to be the true origins of architecture.

\section{The Silt House: A building that shits itself and buries itself}

Drawing on the work of Raimund Abraham, 'The Silt House' project comes out of a desire to propose a new typology for an architecture that could be sited within an intertidal zone in the Thames Estuary. In the spirit of Abraham, this project moves beyond the technocratic architectures currently under investigation for habitation in a flood zone, such as the possibility of a larger and more efficient Thames Barrier located down river, and presents a more lyrical response. The single structure, made of concrete, is located on the south side of the estuary on the Cliffe Marshes of Kent. Historically a salt marsh, the landscape here has been repeatedly claimed by the sea and subsequently protected from it via a series of increasingly complex defence walls, the first dating back to Roman England [1]. The project proposes the removal of the current fortified concrete sea wall at Cliffe, which would allow the Thames to splay and a new salt marsh to form at the apex of the river that will be reclaimed by the sea [2]. The building, or dwelling, can be occupied by a number of people at once, and there is no specified inhabitant. Instead, we might imagine those who would choose to live in such a place - perhaps a community that wishes to live outside orthodox settlements and away from more conventionally civilised locations. It is a lone architecture facilitating a frontier existence sited on the edge of a new flood wilderness, where access to the central electricity grid and water supplies would be limited. The form of the structure is not reminiscent of any vernacular. Instead, the curved, shell-like building is designed to allow water to flow around and over it, and for mud to settle on it [3].

The Silt House proposes an architecture that is explicitly of the ecology and the landscape in which it sits. It can be seen as a conduit attempting to channel the poetics of natural processes, including the very floods that wash over it. To do this, the building must adapt to the tidal environment in two

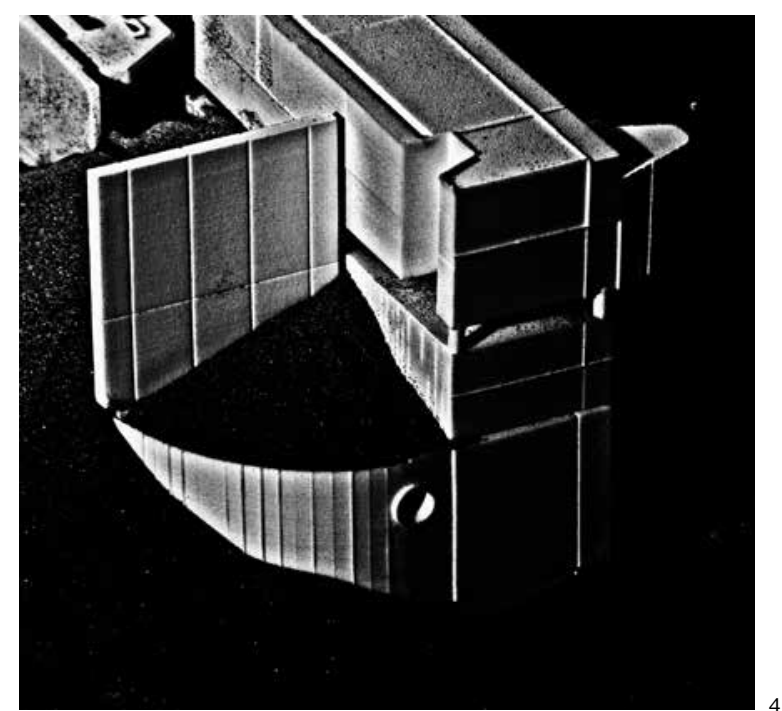

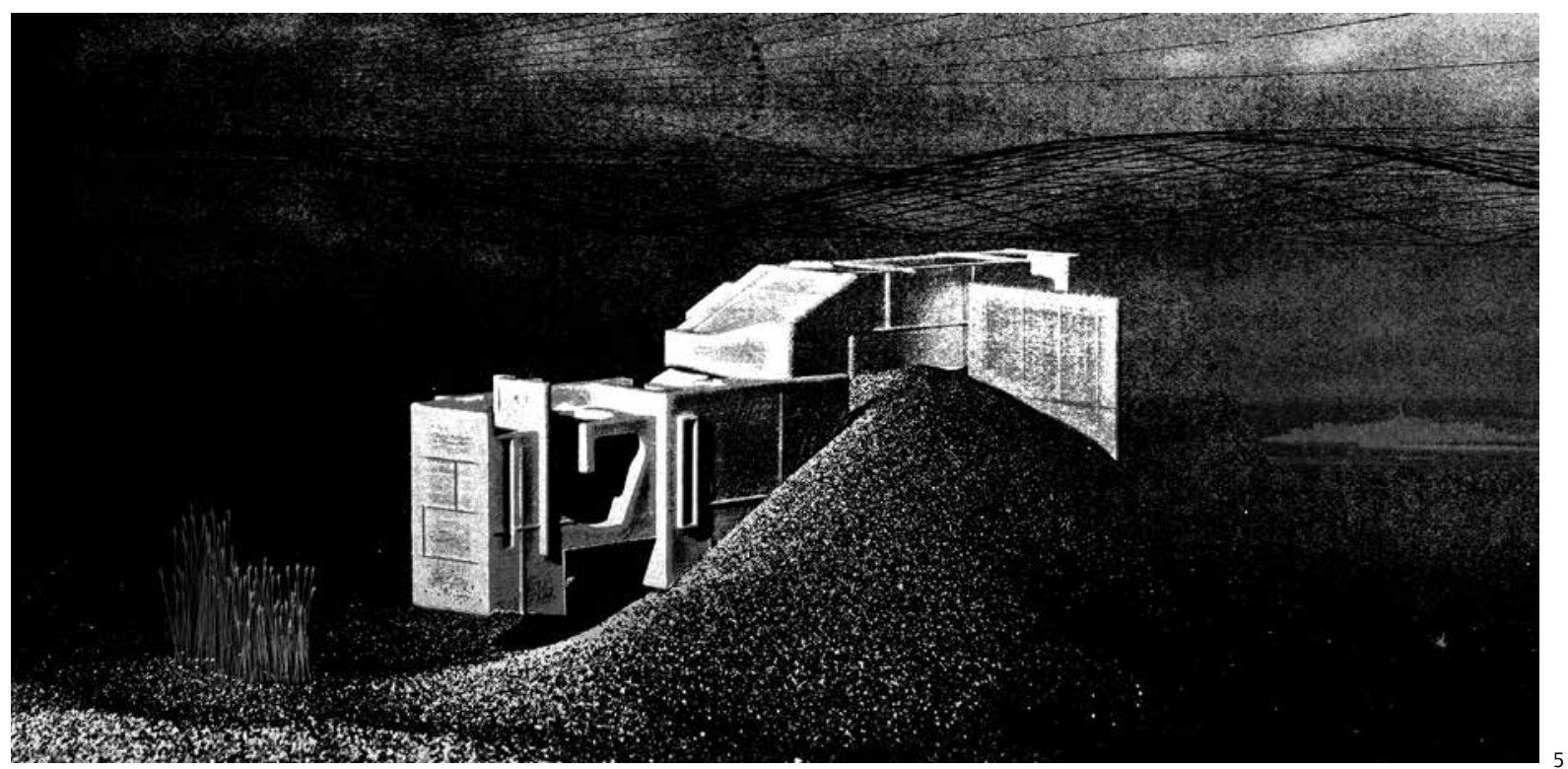


critical ways. Firstly, through floodwater, which is used to clean and sanitise the house and to control the sewage system. The process occurs at high tide, when water is drawn into a system of pipes contained within the walls and floors of the building and is then diverted to the septic tanks which swill wastewater and stored faeces out of a small circular conduit located in the back of the building. Put simply, when the landscape floods, the building shits itself [4]. Secondly, during the winter months, when exposed to harsh North Sea winds, it becomes necessary for the building to temporarily clothe itself to provide increased comfort and insulation to those inhabiting it. To do this, the house buries itself in the silt and sediment of the river. The action increases both the mass of the exterior facade and

\section{Back elevation of Silt House showing \\ sewage conduit (Ass Hole). Model Photo, 2015. \\ 5 'To pile up mounds, to bury the entire body in the earth', the Silt House buried by river sediment during winter. \\ $6 a$ Exploded perspective plan of Silt House, digital scan of ink on Trace, 2015. \\ $6 b$ Exploded perspective plan of Silt House, Digital Collage, 2015}
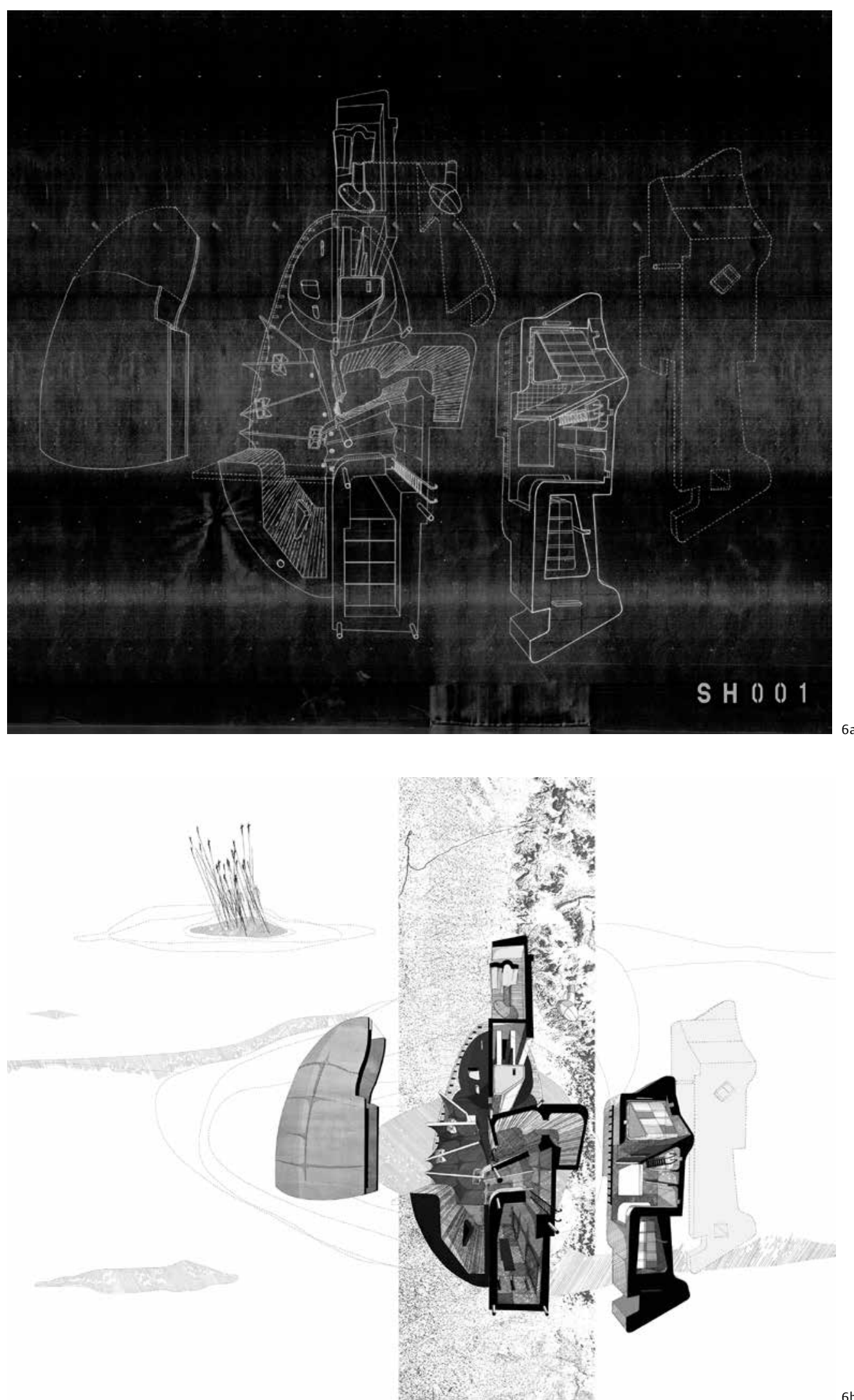


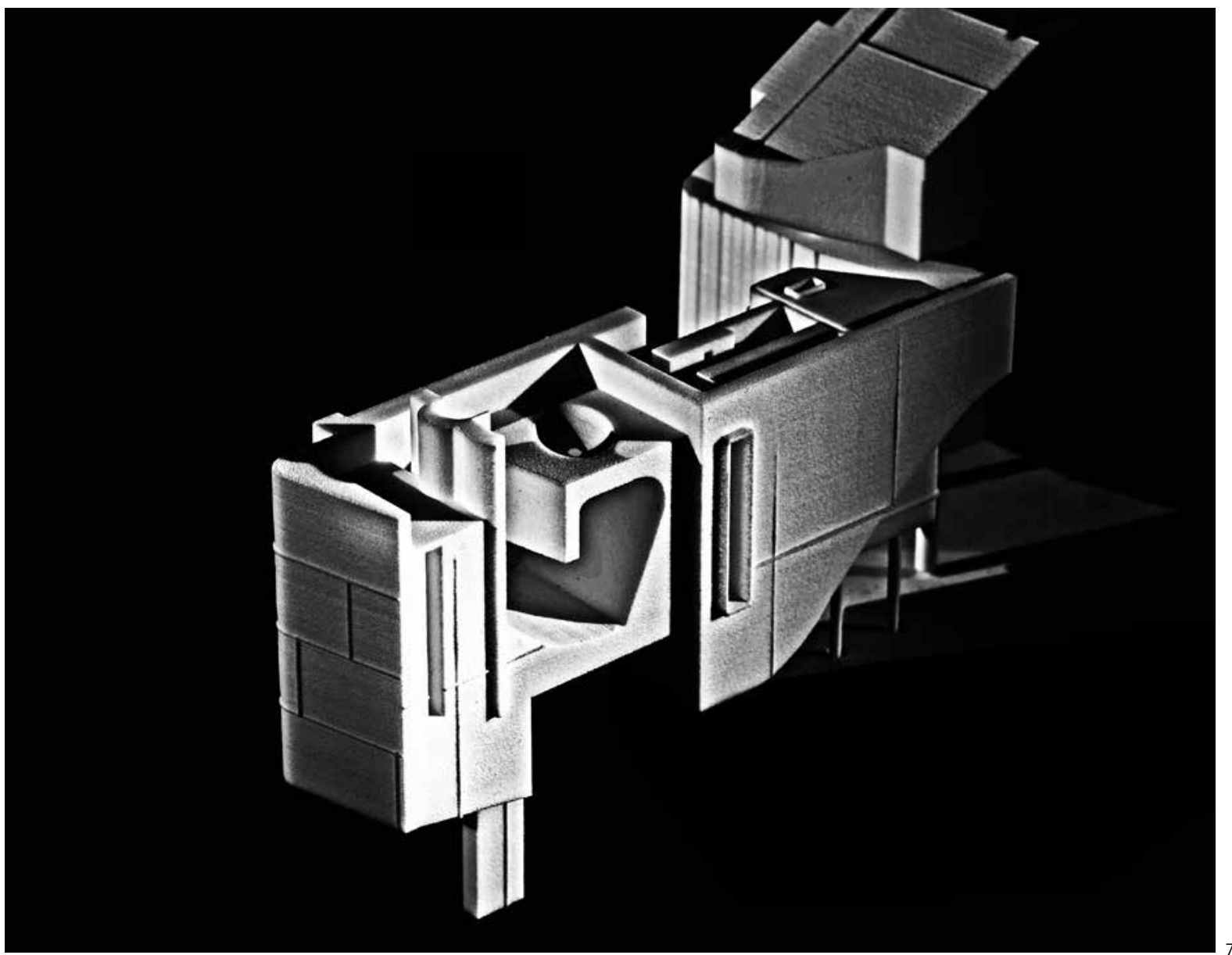

the building's capacity to store heat during the winter. Generating this performance requires a system of nets that encircle the house and slow down the flow of water around the structure, allowing heavier sediment to fall and collect on the roof [5].

Although the particular operations of the building serve clear programmatic and practical necessities, their specific nature, as well as the projection and discarding of sewage and the burial of the building, create an anthropomorphic architecture. The building can be imagined to experience certain fears and desires and to physically react to them: the need for protection, to hide from danger, to be warm.

Not only would the operation of the building develop a more symbiotic relationship with the flood, the design of the interior promotes this

interdependency between occupant and landscape. Inside the Silt House, this is achieved through the destabilising of any typological norm traditionally associated with a house. Instead of movements of vertical planes in relation to the horizontal, seen in the form of more traditional dwellings, the floors, walls, and ceiling of the House undulate like a landscape. Planes rise and fall creating pockets of space that could be used for sleeping and sitting. There is also no central access within the house. Instead, the forms of the walls and floors choreograph the body into a continual contoured procession and stimulate particular types of movement that require balance, poise, and a steady foot, demanding a control and knowledge of one's own body in order to occupy the building safely. Each floor is linked to the other and, due to the particular formal language of the proposal, there is neither a clear hierarchy of floors nor a particular ground datum [6a, 6b] - a condition that is mirrored when the sediment builds up over the house and slowly buries it.

As the floodwater washes over the landscape, it shifts the silt and sediment across the estuary bed. In parallel, the building's formal and spatial organisation sets out to continually alter the relationship of the body to the ground, like Abraham's assertion that architecture begins with a physical and bodily relationship with landscape $[7,8]$. Occupying this architecture allows the inhabitants to readdress their physical relationship to the flood and perhaps their understanding of it. ${ }^{23}$

\section{Reference, reappropriation, and repetition}

Silt House has attempted to draw out the ideas of Abraham. The relationship of the latter to the former should be seen as more than just as an influence. By exploring this relationship we can ask what particular meanings can be generated from a design process that takes existing historical architectural models to inform design in a contemporary context. Analysis can begin with a more detailed look at certain methodologies used within the design process, which developed a distinct reciprocity with the work of Abraham, where not only conceptual strands were drawn out but also critical formal and spatial ideas repeated.

Certain motifs seen across Abraham's 10 Houses project $\left(1970^{-} 3\right)$ were identified. These included 


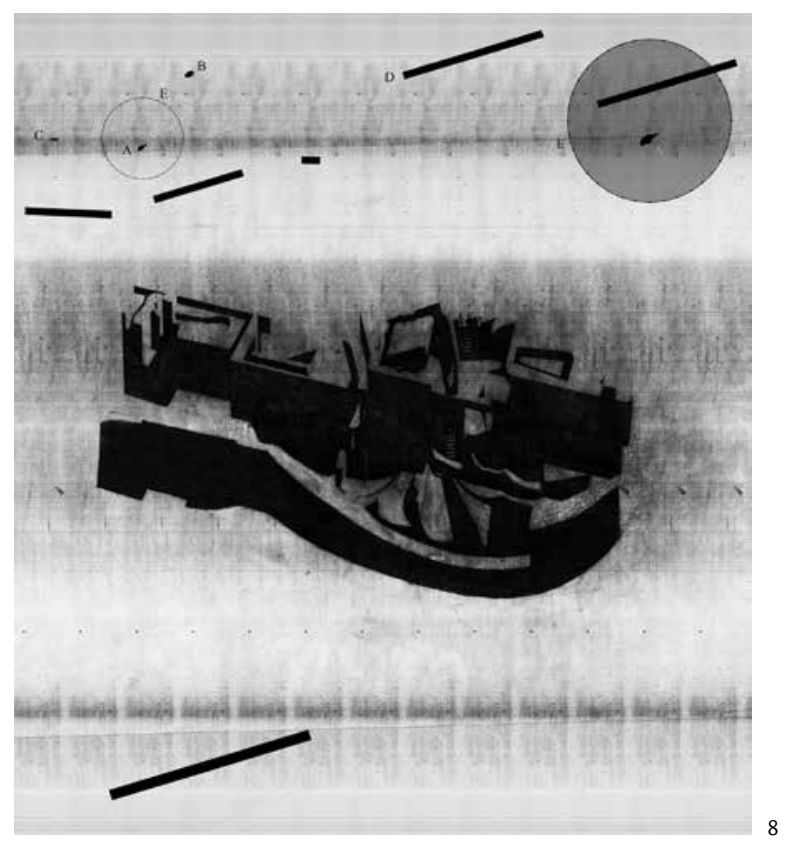

7 Silt House, model photo, 2015.

8 Isometric of shadow

and Silt House and

site plan.

specific materials, burial mounds, and formal components which mimicked natural forms. ${ }^{24}$ Together they were understood to comprise a kind of topological key to Abraham's work - a grammar of a sort which was then developed to shape the spatial and formal logic of the Silt House. For instance, we can see the undulating cloud-like form present in the basement of the Earth-Cloud House (1970) carried over to the Silt House not as stratus-forming vapour but as wave-like forms that echo the way sediment and mud settles after the tide has withdrawn. The semi-burial motif seen in most of the 10 Houses series works its way into aspects of the Silt House as the building is slowly buried beneath the sediment of the estuary mud flats, and the nets that surround allow the sediment to fall onto it's surface. Finally the presentation of spaces, seen in the House with Three Rooms (1972), that seem carved from solid matter (rock), or existing as cast within massive walls, reappears in the Silt House on in the upper floor spaces as well as the back chamber.

It can be argued that there are several outcomes of this self-conscious use of an existing model and, in particular, the extraction of motifs for reuse. This approach can be seen critically as an attempt to ensure that Abraham's ideas are carried forward to develop a more symbiotic architecture where formal and spatial conditions are driven by philosophical and lyrical aspirations. But it is also important to consider meanings that can be determined from the use of repetition in the methodology of the design itself, between the existing model and the new design.

In his 2009 book, Architecture's Desire: Reading the Late Avant-Garde, K. Michael Hays sets out the notion that the formal repetition and reappropriation of motifs from historic architectures was one of the key strategies and considerations undertaken by what he calls the late avant-garde, ${ }^{25}$ with which Abraham could be said to have certain formal and conceptual affiliations. ${ }^{26}$ In particular, Hays states that we see within the work of this period, existing as 'the expanded decade of the $1970{ }^{,},{ }^{27}$ the appropriation and reimagination of forms adapted from the language of modernism such as grids, planes, and primary geometries, as seen, for example, in the work of Le Corbusier as well as De Stijl and the constructivist movements. ${ }^{28}$ This also came through, in the 1970s, in the work of Abraham, in the formal motives of his 10 Houses projects in particular, with their gridded cube forms and walls that jut out from the ground plane at 90 degrees. Hays presents a selection of readings of the meaning of this particular act. However, within the context of this article, and within the framework of the methodologies set up in the Silt House, Hays' most significant argument is that this process was intended as critique of a society that was becoming increasingly obsessed with capitalism and consumption, arguing that 'ideologicalrepresentational engagements of architecture with the expanding consumer society of the 1970 s were probed, and various strategies of distortion, resistance, and reappropriation were devised ${ }^{29}$ One manifestation of this, Hays argues, was through the repetition of existing architectures as attempts to critique developments in postmodernism and the postmodern style - and their gradual appropriation as capitalist iconography: 'Unlike the fully commercialised postmodernism, the late architectural avant-garde keeps its namesake's commitment to rigorous formal analysis, making the material of architecture stand against consumerism. ${ }^{30}$

Here, the repetition of historical models resonates with the Silt House's design processes, where the reappropriation of Abraham's ideas can be read as a means of resistance; not resistance against the developments of the consumer society of the late 1960 and 1970 s but against the consumption of natural resources that would need to occur in order to develop the Thames Estuary as laid out in the TE2100 report. Here, the model of a technocraticallydriven infrastructure which fuels such developments is negated, supplanted with a synthesis following the model of Abraham's architecture, seeking to establish an altogether different proposition of flood defence and idea of architecture and landscape.

Through the development of the design of the Silt House we have seen distinct similarities between the approach of the late avant-garde and with Abraham. But there are also fundamental distinctions to be made. This takes shape in what Hays describes as the rigorous reanalysis of existing forms seen in the late avant-garde towards an architecture of autonomy, or architecture that is about architecture [9]. In doing so, the discipline's cultural discourse cut itself off from the particular social conditions of the time. When discussing the idea of autonomy in the work of Peter Eisenman, for whom Hays is a key protagonist, 


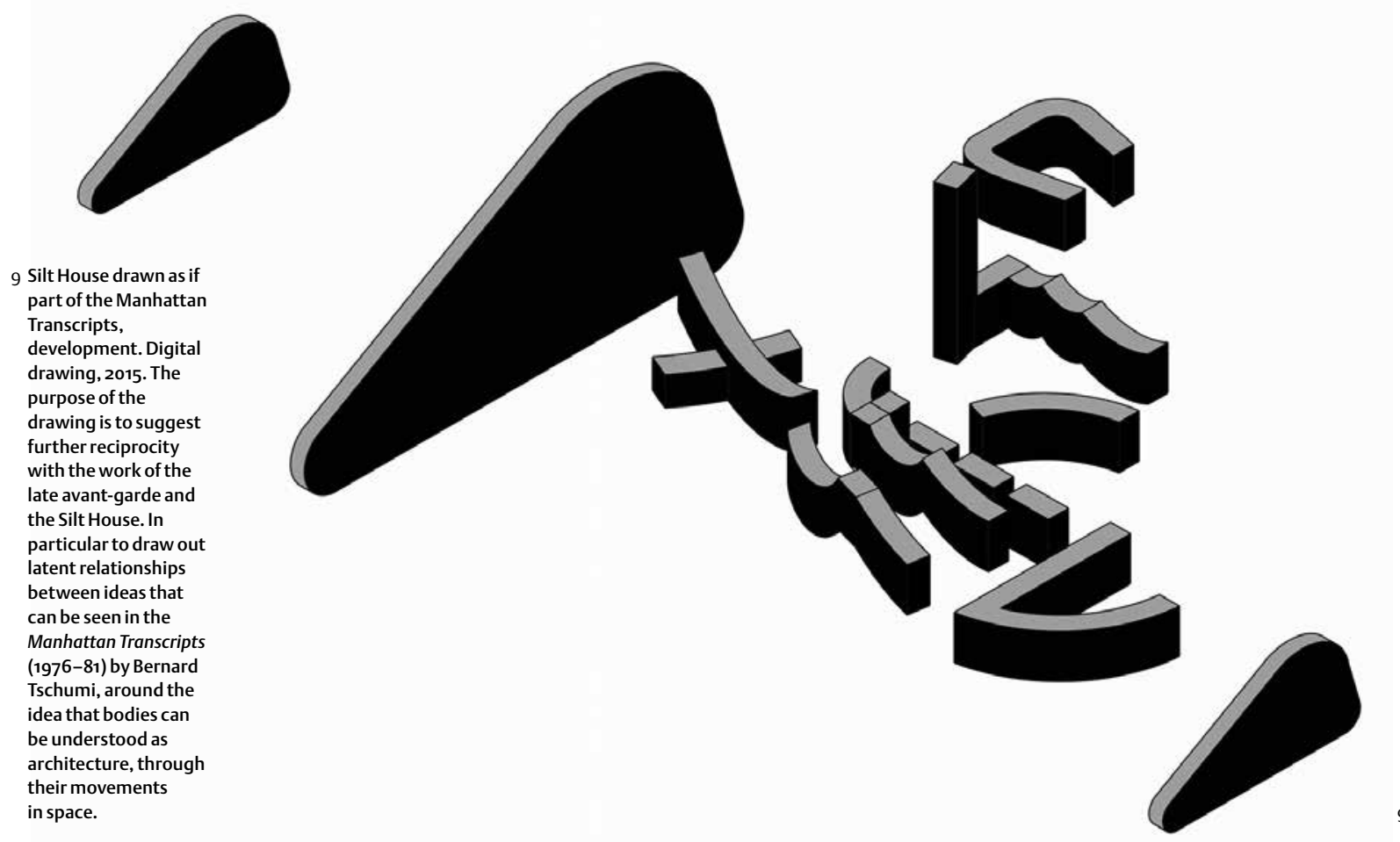

'the price of autonomy is a reduction in and specialisation of form, which becomes cut off from other social concerns' ${ }^{31}$ Hays reiterates this, suggesting that the late avant-garde 'self consciously closes in on its limits rather than opens outward'. ${ }^{32}$ While relying on a formal, conceptual, and spatial vocabulary developed from Abraham, the Silt House does not follow the mould of the late avant-garde's inwardness. Instead the forms it draws on are recontextualised into a new social and political context, challenging the idea of a purely autonomous architectural exploration. This process resonates with the writings of Hilde Heynen who, also against the idea of an autonomy of distance, states that 'architectures should have a relationship to, and be critical of, the social conditions of their time'. ${ }^{33}$ In highlighting this she explores the potential criticality that can occur when the autonomous is mediated back into any social or political context through it's engagement with heteronomous conditions such as 'site', 'clients', and the profit calculations that exists with any built development. For this criticality to be present within an architecture, she acknowledges that any design has an autonomous moment. In her article 'A Critical Position for Architecture?', published in 2007, she states that:

architectural works, through their mimetic relation with programme, site, materials, historical, and social context, can critically reflect upon their social condition. This critical reflection is possible because architecture has an autonomous moment - it is not entirely determined by heteronomous forces such as technical, functional, or economic requirements. ${ }^{34}$ In this sense, the reciprocity between past and present historical models recontexulised in the Thames Estuary presents itself within Silt House as a means towards reciprocity between the social and the political with architecture, and furthermore, a reciprocity between conditions of landscape and architecture. In this way, the project provides us with a unique spatial and formal proposition for the future flooded Thames Estuary.

\section{Notes}

1. Kurt Lambeck, 'Sea Level and Global Ice Volumes From the Last Glacial Maximum to the Holocene', in National Academy of Sciences of the United States of America, 111:43 (2014). See also a report on the paper: Oliver Milman, 'Sea Level Rise Over Past Century Unmatched in 6,0oo Years, Says Study', in The Guardian, 13 October (2014), available online: <http://www. theguardian.com/environment 2014/oct/14/sea-level-riseunmatched-6ooo-years-globalwarming) $>$ (accessed 15 October 2014).
2. Intergovernmental Panel on Climate Change, Climate Change 2014: Impacts, Adaptation, and Vulnerability: Summary for Policymakers, p. 22, available online: $<$ http://ipcc-wg2.gov/AR5/images/ uploads/WG2AR5_SPM_FINAL.pdf) > (accessed 15 October 2014).

3. Environment Agency, TE2100 Plan Managing Flood Risk through London and the Thames Estuary (London: Environment Agency, 2012), available online: <https://www.gov. uk/government/publications/ thames-estuary-210o-te210o> (accessed 15 October 2014).

4. Matt McGrath, 'Sea Surrender Plan to Ease Flood Fears on South Coast', in BBC News, 4 November (2013), available online: <http://www.bbc. co.uk/news/scienceenvironment-24770379> (accessed 12 December 2013). The article includes commentary from Karen Thomas from the Environment Agency on the successes experienced at Abbotts Hall Farm in Essex.

5. Ibid.

6. Environment Agency, TE2100, p. 30.

7. Ibid.

8. Paul Brown, 'Flood Risk Could Make 300,ooo Homes Uninsurable', in The Guardian, 1 February (2005), 
available online: <http://www. theguardian.com/money/2005/ feb/o1/insurance.greenpolitics> (accessed 15 October 2014).

9. Andrew Gilham, The Environment Agency's flood and coastal risk manager, quoted in McGrath, 'Sea Surrender Plan'.

10. This dichotomy is also highlighted, and explored in more detail, in: Peg Rawes, Relational Architectural Ecologies: Architecture Nature and Subjectivity (London: Routledge, 2013), pp. 1-13. Rawes seeks to identify the contradictions that exist between market-driven interests of architectural and built environmental practices, environmental policy, and the actuality of climate change phenomena.

11. Environment Agency, TE2100, p. 28.

12. A portfolio is online at: $<\mathrm{http}: /$ www.waterstudio.nl> (accessed 15 October 2014).

13. See:<http://www.bacahomes.co.uk/ index.php/build/living-with-water> (accessed 15 October 2014).

14. Jonathan Hill, Immaterial Architecture (London: Routledge, 2006), p. 2.

15. Ibid., pp. 6-14.

16. Ibid., p. 30.

17. Norbert Miller, 'Imagination and the Calculus of Reality Raimund Abraham's Architectural Oeuvre', in Raimund Abraham, [Un]built, ed. by Brigitte Groihofer (Vienna: Springer Verlag, 1996), p. 10

18. Raimund Abraham, 'The Silence of the Muses', Ibid., p. 105. The text is a Lecture given by Abraham for the International Competition for the New Acropolis Museum in Athens, 1991. See also: Lecture at Athens School of Architecture, National Polytechnic, 20 March (1991), Ibid., p. 108.

19. Raimund Abraham, 'In Anticipation of Architecture, Fragmentary Notes', Ibid., p. 102.

20. Raimund Abraham, 'The Reality of the Unbuilt', Ibid., p. 111. Lecture given by Abraham in Vienna in 1986 as part of a series of lectures organised by the Austrian Museum of Applied Arts. Please note the Heidegger quote referenced within this quotation is not indicated in the text but is most probably a reference to: Martin Heidegger, on the Way to Language (New York: Harper and Row, 1971), p. 121. It is worth noting that Heidegger, in $O n$ the Way to Language indicates that design is a name given to the concept of the 'unity of the being of language'

21. Raimund Abraham, 'In Anticipation of Architecture,
Fragmentary Notes', Ibid., p. 101. 22. Ibid., p. 102.

23. An earlier text about the Silt House appears in: Matthew Butcher, 'The Flood House II', P.E.A.R.: Paper For Emerging Architectural Research, 6, January (2014), pp. 24-31.

24. Raimund Abraham's 10 Houses project existed as a series of ten theoretical projects developed between 1970 and 1973. The drawings are particular in their use of coloured pencil and graphite and all show isolated dwellings within a non-specified landscape. An extensive catalogue of reproductions of the projects can be found in Raimund Abraham, [Un]built, pp. 53-67.

25. The term Late Avant-Garde comes directly from K. Michael Hays. It is his terminology developed to separate his understanding of this period of architectural production from others. In particular from the much more negatively driven definition set out by Peter Burger, in his book Theory of the Avant-Garde, in which he refers to this period of cultural production that used early modern forms, as neo-avant-garde. See: K. Michael Hays, Architecture's Desire: Reading the Late Avant-Garde (Cambridge, MA: MIT Press, 2010), pp. 4-12 and Peter Burger, Theory of the Avant-Garde, trans. by Michael Shaw (Minneapolis: University of Minnesota Press, 1984), p. 148.

26. Hays gives certain descriptions of what he considers to be key attributes that identify the late avant-garde. As described in his texts, these include the reference and reappropriation of modernist forms but also the desire to embody and define the origins of architecture. The examples he explores, which embody these attributes, are the work of Aldo Rossi, Peter Eisenman, John Hedjuk, and Bernard Tschumi. Raimund Abraham, although not referenced in Architecture's Desire, is presented in this text as demonstrating conditions within his work that could be said to have also embodied some of the attributes outlined by Hays. As well as producing key works at the same time and in the same city as Hedjuk and Eisenman, it is also worth noting the relationship to the ideas of Abraham outlined in this text and Hays' assertion, when describing the work of the late avant-garde that 'the obsessive search in this work for architecture's fundamental codes and principles'. Hays, Architecture's Desire, p. 16
27. Ibid., p. 2

28. Ibid., p. 3

29. Ibid., p. 2.

30. Ibid., pp. 11-12.

31. Ibid., p. 10.

32. Ibid., p. 12.

33. Hilde Heynen, 'A Critical Position

for Architecture?', in Critical Architecture, ed. by Jane Rendell, Jonathan Hill, Murray Fraser, and Mark Dorrian (London: Routledge, 2007), p. 48. This definition of 'critical' presented by Heynen can be understood as relating to definitions of critical theory set out by Max Horkheimner and the Frankfurt School. Heynen states 'Critical Theory does not wish to accept social reality as it is, but always questions its legitimation and justification.'

34. Ibid., p. 49. See also: Hilde Heynen, Architecture and Modernity: A Critique (Cambridge MA: MIT Press, 1999).

\section{Illustration credits}

arq gratefully acknowledges

Author, all images, with thanks to

Tim Yue

\section{Acknowledgements}

I would like to thank Sarah

Handelman, Jonathan Hill, Elizabeth Dow, Jane Rendell, and Mark Smout for the support and advice during the production of this project and this text.

\section{Author biography}

Matthew Butcher is a designer and academic working across the fields of architecture, art, and performance art. He founded the design practice Post Works with Melissa Appleton in 2009. He is Lecturer in Architecture and Performance and Director of the BSc. Architecture Programme at the Bartlett School of Architecture. Recent projects and exhibitions include 'Stage City' (exhibited at the V\&A Museum, Prague Quadrennial and the Royal Academy); 'Wash House Carnival Arena' (exhibited in Guimarães, Portugal as part of the city's 2012 European Capital of Culture art and architecture programme); and '2EmmaToc/Writtle Calling' a temporary radio station in Essex, which was voted in Artforum as one of the best projects of 2013. His work has also been exhibited at the Architectural Association and the Architecture Foundation in London. Matthew is co-founder and editor of the architectural newspaper P.E.A.R.: Paper for Emerging Architectural Research.

Author's address

Matthew Butcher

m.butcher@ucl.ac.uk 